\title{
Histopathological Aspects of Placental Lesions in Mild and Severe Pre-Eclampsia in a Population of Cameroonian Women
}

\author{
Félix Essiben ${ }^{1}$, Ayissi Gregory², Belinga Etienne', Ndolo Kondo Astrid ${ }^{2}$, \\ Ngo Dingom Madye Ange ${ }^{3}$, Ebong Cliford Ebontane', Ojong Samuel Atomveng3, Foumane Pascal ${ }^{4}$ \\ ${ }^{1}$ Yaoundé Central Hospital, Department of Obstetrics and Gynecology, Faculty of Medicine and Biomedical Sciences, \\ The University of Yaoundé I, Yaoundé, Cameroon \\ ${ }^{2}$ Department of Obstetrics and Gynecology, Faculty of Medicine and Biomedical Sciences, The University of Yaoundé I, Yaoundé, \\ Cameroon \\ ${ }^{3}$ Central Maternity, Yaoundé Central Hospital, Yaoundé, Cameroon \\ ${ }^{4}$ Yaounde Gyneco-Obstetric and Pediatric Hospital, Department of Obstetrics and Gynecology, Faculty of Medicine and \\ Biomedical Sciences, The University of Yaoundé I, Yaoundé, Cameroon \\ Email: *essibenx@yahoo.com
}

How to cite this paper: Essiben, F., Gregory, A., Etienne, B., Astrid, N.K., Ange, N.D.M., Ebontane, E.C., Atomveng, O.S. and Pascal, F. (2022) Histopathological Aspects of Placental Lesions in Mild and Severe Pre-Eclampsia in a Population of Cameroonian Women. Open Journal of Obstetrics and Gynecology, 12, 154-168. https://doi.org/10.4236/ojog.2022.122016

Received: January 18, 2022

Accepted: February 22, 2022

Published: February 23, 2022

Copyright $\odot 2022$ by author(s) and Scientific Research Publishing Inc. This work is licensed under the Creative Commons Attribution International License (CC BY 4.0).

http://creativecommons.org/licenses/by/4.0/ (c) (i) Open Access

\begin{abstract}
Background: Pre-eclampsia (PE) frequently leads to adverse maternal and foetal outcomes in our setting. The pathophysiology is strongly linked to placental development. We aimed to study placental lesions associated with PE in a population of Cameroonian women. Methods: We conducted a crosssectional, analytical study in three university teaching hospitals in Yaounde namely, the Yaounde Central Hospital, the pathology laboratory of the Yaounde University Hospital Centre, and the Yaounde Gynaeco-Obstetric and Paediatric Hospital. The study spanned 8 months from January $1^{\text {st }}$ to September $1^{\text {st }}, 2021$. Placental analysis was carried out as per standard protocol. The study included 101 parturients with pre-eclampsia. These were divided into two groups, with groups 1 and 2 being made of patients with mild preeclampsia $(n=40)$, and severe pre-eclampsia $(n=61)$, respectively. Results: The mean ages of the two groups were $29.93 \pm 7.36$ versus $28.28 \pm 7.18$ ( $\mathrm{p}=$ 0.267 ) for patients with mild and severe pre-eclampsia respectively. Low socioeconomic status was the most frequently identified risk factor in both groups (59\%). Patients' history revealed that the women with severe pre-eclampsia tended to have poor pregnancy follow-up compared to those with mild preeclampsia $(\mathrm{p}<0.05)$. Also, the placentas of patients with severe pre-eclampsia weighed significantly less than those of patients with mild pre-eclampsia ( $454.4 \pm 122$ vs. $511.7 \pm 125 ; \mathrm{p}<0.05)$. Pre-eclampsia-related lesions were significantly greater in patients with severe disease $(p<0.05)$. Conclusion:
\end{abstract}


PE-related placental lesions in our context are multiple and diverse especially in severe disease, and these arise as a result of defective maternal vascular perfusion.

\section{Keywords}

Preeclampsia, Placental Lesions, Histological Aspects, Placental Dysfunction, Cameroon

\section{Introduction}

Pre-eclampsia refers to the development of hypertension and proteinuria or hypertension and significant end organ dysfunction, with or without proteinuria after 20 weeks of gestation, or in the postpartum period in a previously normotensive woman [1]. The global prevalence of pre-eclampsia is $4.6 \%$. In Africa, it is $44.0 \%$ while Mboudou et al. reported a prevalence of $4.97 \%$ in Cameroon [2] [3] [4]. It is the most morbid of the hypertensive conditions in pregnancy and is the second leading cause of maternal mortality in the world, after postpartum haemorrhage [5].

Epidemiological and experimental data demonstrate that placental tissue underlies the pathophysiology and development of the disease and indicate that pre-eclampsia is reversible within days to weeks of placental delivery [6] [7]. In pre-eclampsia, cytotrophoblast cells infiltrate the decidual portion of the spiral arteries but fail to penetrate their myometrial segment, resulting in the abnormal development of large, tortuous vascular channels which are created as the elastic muscularis is replaced by fibrinoid material [8]. Thus, the vessels remain narrow leading to hypoperfusion, hypoxia, placental ischaemia, and the eventual release of anti-angiogenic factors into the maternal circulation. This release is in turn responsible for a generalised endothelial disease which explains the symptomatic variety in pre-eclampsia [9] [10].

Classically, placental hypotrophy is the main macroscopic lesion identified in pre-eclampsia. This however remains controversial as hyperplacentotic states are usually associated with PE. Microscopically, the main parenchymal finding in pre-eclampsia is acute arteriosis. This is marked by fibrinoid necrosis of the vascular wall with an accumulation of lipid-laden "foamy" macrophages and a mononuclear perivascular infiltrate [11]. Vascular ectasia and thrombi may also be present. Pathologically, the diagnosis is made by examining the vessels of the decidua parietalis, a procedure which is usually difficult to perform in routine practice as it requires curettage. This difficulty justifies the interest in the other placental manifestations of pre-eclampsia such as villous hypoplasia, and placental infarcts, which indicate maternal vascular hypo-perfusion, and which constitute associated or progressive forms of placental pathology [12].

The absence of data describing the histopathological aspects of placental lesions in pre-eclampsia in a typically African population (Cameroon), motivated 
our desire to carry out this cross-sectional analytical study.

\section{Methods}

\subsection{Study Site}

We conducted a prospective, cross-sectional and analytic study over 8 months from January $1^{\text {st }}$ to September $1^{\text {st }}$, 2021. Patients were enrolled in two university teaching hospitals in Yaounde namely the Yaounde Central Hospital, and the Yaounde Gynaeco-Obstetric and Paediatric Hospital, while the histopathological analysis of the placental samples was performed at the pathology laboratory of the Yaounde University Hospital Centre.

\subsection{Patients}

Eligible parturients with pre-eclampsia were included for the study and divided into two groups. Group 1 consisted of those with mild pre-eclampsia (MPE), while group 2 consisted of patients with severe pre-eclampsia (SPE). High blood pressure (HBP) referred to a systolic blood pressure (SBP) $\geq 140 \mathrm{mmHg}$ and/or diastolic blood pressure (DBP) $\geq 90 \mathrm{mmHg}$ taken at rest on at least two occasions $4 \mathrm{~h}$ apart. Proteinuria was considered significant for values equal to or greater than " $2+$ " and/or $300 \mathrm{mg} / 24 \mathrm{~h}$

Mild pre-eclampsia referred to SBP values ranging from $110 \mathrm{mmHg}$ - 159 $\mathrm{mmHg}$ and DBP values $<110 \mathrm{mmHg}$, associated to significant proteinuria after 20 weeks of pregnancy or in the postpartum period in a previously normotensive woman. These definitions were set as per diagnostic criteria proposed by the International Society for the Study of Hypertension in Pregnancy (ISSHP) [13] [14]. Likewise, pre-eclampsia was considered severe in patients who presented:

- Severe hypertension associated to significant proteinuria

- Signs of clinical severity such as severe headaches resistant to regular analgesics, blurred vision, scotoma or photophobia, tinnitus, constrictive epigastralgia and oliguria defined by a diuresis of less than $0.3 \mathrm{mls} / \mathrm{hour}$.

- Biological severity signs such as the HELLP syndrome (Haemolysis, Elevated Liver Enzymes, Low Platelet) and renal failure (serum creatinine $>1.1 \mathrm{mg} / \mathrm{dL}$ or $97.2 \mathrm{mmol} / \mathrm{L}$, or a doubling of the serum creatinine concentration in the absence of other renal disease).

According to the Tennessee classification [15], HELLP syndrome is characterised by:

1) Haemolysis, established by at least two of the following:

- A peripheral blood smear with schistocytes;

- Serum bilirubin $\geq 1.2 \mathrm{mg} / \mathrm{dL}(20.52 \mathrm{mmol} / \mathrm{L})$;

- Low serum haptoglobin ( $\leq 25 \mathrm{mg} / \mathrm{dL}$ ) or lactate dehydrogenase (LDH) titres $\geq 2$ times normal (based on laboratory-specific reference ranges);

- Severe anaemia that is not related to haemorrhage.

2) Elevated liver enzymes

- Aspartate aminotransferase (ASAT) or Alanine aminotransferase (ALAT) ti- 
tres $\geq 2$ times the normal (based on specific laboratory reference ranges).

3) Low platelet count: $<100,000$ cells $/ \mu 1$

\subsection{Study Variables}

For this study, we were interested in socio-demographic data (age, socio-economic status, religion), clinical data (parity, gestational age, pregnancy follow-up, age of pregnancy at delivery, notion of a new partner, aspirin intake, placental weight), and placental lesions (infarcts, signs of accelerated villous maturation, state of syncytial nodes, calcifications).

\subsection{Procedure}

\subsubsection{Approach to Patients}

We made sure to build rapport with the patients before explaining the purpose of our study. We then sought for and obtained their signed or verbal consent, following which we anonymously assigned them identification and sample matching codes.

Afterwards, the patients underwent a complete physical examination. Missing data from the interview and physical examination were taken from the patients' medical records and recorded on anonymised pre-tested data collection cards.

\subsubsection{Placental Tissue Retrieval}

In order to carry out placental histopathological analysis, the placentas of study participants were weighed after cord sectioning and membrane removal. Next, 2 $-3 \mathrm{~cm}$ squares of placental tissue were taken, one from the centre of the placenta and the other from the periphery. These were then washed in isotonic saline solution to remove excess blood and immediately placed in a properly labelled, sterile vials filled with $100 \mathrm{ml}$ of neutral $10 \%$ formalin for tissue fixation. The biopsies were immediately transported to the pathology laboratory for onward analysis.

\subsubsection{Macroscopic Examination}

This was done when tissue fixation was deemed adequate. The fragments were then placed in cassettes that were legibly marked with registration numbers. The number of cassettes was noted on the worksheet, along with information on whether the transmitted specimen was entirely evaluated.

\subsubsection{Material Preparation}

\section{1) Dehydration, thinning and impregnation}

The aim of this phase was to replace the water in the tissues with a neutral substance (paraffin in our case) that hardened the samples towards obtaining thin sections. It was done in an apparatus called the dehydration automaton (Leica model TP 1020). The cassettes were placed in a rack, which was in turn was immersed in each of the trays for a specific amount of time, thanks to an automatic rotation system. The trays were distributed as follows:

- $1^{\text {st }}$ tray: buffered formalin, to perfect the fixation (1 h $\left.30 \mathrm{~min}\right)$. 
- $2^{\text {nd }}$ to $8^{\text {th }}$ trays: alcohol of increasing concentration from 50 degrees to 100 degrees, in order to ensure tissue dehydration $(7 \mathrm{~h})$.

- $9^{\text {th }}$ and $10^{\text {th }}$ trays: Xylene which allowed for the elimination of the alcohol (lightening) allowing paraffin to penetrate the sample $(2 \mathrm{~h})$.

- $11^{\text {th }}$ and $12^{\text {th }}$ trays: allowed for liquid paraffin to impregnate the tissue samples (3h).

\section{2) Coating}

This was done using a mounting station (Leica Histoscore Arcadia) consisting of a paraffin dispenser and a cooling plate. The sample was then placed in a mould and fixed to the bottom by placing the mould on the cooling plate. A variable amount of paraffin was added and then the mould was placed on the plate for 15 minutes to obtain a block that could be cut.

\section{3) Microtome sectioning}

This was done using a Leica RM 2245 microtome. The coated block was inserted firmly into the microtome holder. The block was first roughened with 15-to-20-micron cuts and then the actual cuts were obtained by making 3-to5-micron thick ribbons.

\section{4) Making the blades}

The selected cut was detached from the ribbon with a scalpel and immersed in a water bath for 30 seconds and then spread on a slide with an identification number. This was followed by draining and then drying in an oven.

\section{5) Colouring}

It consisted of dewaxing by passing the samples through 3 xylene tanks and then passing the same through 3 alcohol baths of increasing degrees followed by rehydration in 2 water tanks. Subsequent steps consisted of:

$\checkmark$ Haematoxylin immersion (5 - 7 minutes)

$\checkmark$ Rinsing under running water (13 minutes)

$\checkmark$ Brief passage in $1 \%$ acetic water

$\checkmark$ Rinsing under running water (13 minutes)

$\checkmark$ Passage through ammonia to dye the cores with blue stain (5 seconds)

$\checkmark$ Rinsing under running water (1 to 3 minutes)

$\checkmark$ Eosin staining (2 - 4 minutes)

$\checkmark$ Rinsing under running water ( $1-3$ minutes)

$\checkmark$ Passage through an absolute alcohol bath

$\checkmark$ Passage through a xylene bath

\section{6) Assembly}

Samples were placed on the slide after applying a few drops of synthetic resin (Eukitt). The slides were then labelled and placed in trays before being given to the pathologists for analysis and interpretation.

\section{7) Microscopic examination}

It was done on a microscope (LEICA DM LED 1000) by the pathologist. The images were obtained with the standard cell Sens software using a d27 camera.

\section{8) Lesion mapping}

The histological lesions of pre-eclampsia [12] [16]-[21] we were on the loo- 
kout for included infarction, signs of accelerated villous maturation, increased syncytial nodes and calcifications.

\subsection{Data Management}

Data analysis was done using the SPSS 23.0 software. We determined the frequency of occurrence of placental lesions in MPE and SPE and subsequently compared the frequency of occurrence of these lesions across the 2 groups. The comparison of the means of the two independent groups was carried out using the Student $t$-test and the comparison of the categorical variables was done using a chi-square test with a p-values at 0.05 considered to be significant.

\subsection{Ethical and Administrative Considerations}

Our study was carried out in accordance with the national guidelines in Cameroon. Ethical approval to conduct this study was obtained from the ethical and institutional committee of the University of Yaounde I. Clinical data and biological samples were obtained after informed consent from all participants. Participation was strictly voluntary, with no restrictions if the participant decided to withdraw from the study.

\section{Results}

In total, we recruited 101 patients, 40 with MPE (group 1) and 61 with SPE (group 2).

\subsection{Socio-Demographic Data}

The median age of the patients was 30 years (ranging from 15 to 42 years). Table 1 compares the ages and socioeconomic statuses of the study population. Patients with MPE were younger than those with SPE $(29.9 \pm 7.4$ vs $28.3 \pm 7.2)$ however there was no statistically significant difference between the two groups $(\mathrm{p}=0.27)$. The socioeconomic level of all the women with preeclampsia was low (58.4\%) irrespective of the groups with no statistically significant difference between the groups $(\mathrm{p}=0.32)$.

Table 1. Distribution of the study population by age, socio-economic and educational status.

\begin{tabular}{ccccc}
\hline & \multicolumn{5}{c}{ Pre-eclampsia } \\
\hline Variable & Total & Light & Severe & \\
& $\mathrm{N}=101$ & $\mathrm{n}=40$ & $\mathrm{n}=61$ & $\mathrm{p}$ \\
\hline Age (mean \pm SD) & $28.93 \pm 7.18$ & $29.93 \pm 7.36$ & $28.28 \pm 7.18$ & 0.267 \\
\hline Socio-economic status & & & \\
\hline Low (<200 US dollars) & $(58.4)$ & $21(52.5)$ & $38(62.3)$ & 0.317 \\
Medium (200 - 400 US dollars) & $36(35.6)$ & $15(37.5)$ & $21(34.4)$ & \\
High (>400 US dollars) & $6(5.9)$ & $4(10.0)$ & $2(3.3)$ & \\
\hline
\end{tabular}

$\mathrm{P}=\mathrm{p}$-value ${ }^{\star}=\mathrm{p}$-value $<0.05$ 


\subsection{Clinical Data}

Table 2 presents the clinical data of the patients. The median gravidity in our study population was 3 with extremes of 1 to 5 . Also, there was a median parity of 1 with extremes in patients with MPE and SPE, meanwhile there was no significant difference between the two study groups. SPE appeared earlier on in the course of pregnancy compared to MPE, but the difference was not statistically significant ( $36.5 \pm 3.7$ weeks vs $37.6 \pm 3.1$ weeks; $\mathrm{p}=0.13)$. Patients with SPE were more likely to have a poor pregnancy follow-up compared to those with MPE $(55.7 \%$ vs $35 \% ; p=0.4)$. A small proportion of pre-eclamptic women had a history of a new partner $(5.9 \% ; 6 / 101)$, while $51.5 \%$ (52/101) of pre-eclamptic women received aspirin prophylaxis. There was no statistically significant difference across the groups with regards to the notion of a new partner $(4.9 \%$ vs. $7.5 \% ; \mathrm{p}=0.81)$ or the use of aspirin prophylaxis ( $52.5 \%$ vs. $50 \% ; \mathrm{p}=0.59$ ).

Table 2. Distribution of the study population by clinical Characteristics.

\begin{tabular}{|c|c|c|c|c|}
\hline Variables & $\begin{array}{c}\text { Total } \\
\mathrm{N}=101\end{array}$ & $\begin{array}{c}\text { MPE } \\
\mathrm{n}=40\end{array}$ & $\begin{array}{c}\text { SPE } \\
\mathrm{n}=61\end{array}$ & $\mathrm{p}$ \\
\hline Gravidity (median/IQ) & $3.00(1.00-5.00)$ & $3.00(1.00-4.75)$ & $3.00(1.00-5.00)$ & 0.653 \\
\hline G1 & $35(34.7)$ & $11(27.5)$ & $24(39.3)$ & \\
\hline G2-3 & $22(21.8)$ & $12(30.0)$ & $10(16.4)$ & \\
\hline G4-5 & $29(28.7)$ & $13(32.5)$ & $16(26.2)$ & \\
\hline G6+ & $15(14.9)$ & $4(10.0)$ & $11(18.0)$ & \\
\hline Parity (median/IQ) & $1.00(1.00-3.00)$ & $1.00(1.00-3.00)$ & $1.00(1.00-3.00)$ & 0.909 \\
\hline P0 & $21(20.80)$ & $7(17.50)$ & $14(23.00)$ & \\
\hline P1 & $34(33.70)$ & $16(40.00)$ & $18(29.5)$ & \\
\hline P2-3 & $26(25.70)$ & $10(25.00)$ & $16(26.20)$ & \\
\hline $\mathrm{P} 4+$ & $20(19.80)$ & $7(17.50)$ & $13(21.30)$ & \\
\hline AG (average $\pm S D$ ) & $36.89 \pm 3.48$ & $37.55 \pm 3.08$ & $36.46 \pm 3.68$ & 0.126 \\
\hline \multicolumn{5}{|l|}{ Prenatal follow-up } \\
\hline Yes & $53(52.5)$ & $26(65.0)$ & $27(44.3)$ & $0.041^{*}$ \\
\hline No & $48(47.5)$ & $14(35.0)$ & $34(55.7)$ & \\
\hline \multicolumn{5}{|l|}{ New partner } \\
\hline Yes & $6(5.9)$ & $3(7.5)$ & $3(4.9)$ & 0.809 \\
\hline Not & $95(94.1)$ & $37(92.5)$ & $58(95.1)$ & \\
\hline \multicolumn{5}{|l|}{ Taking aspirin } \\
\hline Yes & $52(51.5)$ & $20(50.0)$ & $32(52.5)$ & 0.591 \\
\hline Not & $49(48.5)$ & $20(50.0)$ & $29(47.5)$ & \\
\hline
\end{tabular}

$\mathrm{P}=\mathrm{p}$-value, ${ }^{\star}=\mathrm{p}$-value $<0.05, \mathrm{IQ}=$ quartile interval, $\mathrm{SA}=$ weeks of amenorrhea, $\mathrm{G} 0=$ nulligravid, G1 = primigravid, G2-3 = pauci-gravid, G-5 = multigravida G6 $+=$ grand multigravida, $\mathrm{P} 0=$ nulliparous, $\mathrm{P} 1=$ primiparous, $\mathrm{P} 2-3=$ pauciparous, $\mathrm{P} 4+=$ multiparous, GA: gestational age, $\mathrm{SD}$ : standard deviation. $\mathrm{P}=\mathrm{p}$-value, ${ }^{*}=\mathrm{p}$-value $<0.05$. 


\subsection{Histological Data}

Table 3 shows the histological characteristics of the placentas of pre-eclamptic women. The placentas in patients with SPE weighed significantly less than those with MPE ( $454.4 \pm 121$ vs. $511.7 \pm 125, \mathrm{p}=0.02)$.

Table 4 defines placental lesions by the severity of pre-eclampsia. These placental lesions were significantly greater in patients with SPE $(p<0.001)$ compared to patients with MPE. Villous maturation lesions were more prominent in SPE with $19.7 \%$ (12/61) of placentas having intense villous maturation lesions (Figure 1). Infarction as described in Figure 2, was more common in placentas from patients with SPE $(21.3 \%(13 / 61)$ versus $5 \%(2 / 40) ; \mathrm{p}=0.024)$. Syncytial nodes (Figure 3 ) were significantly more frequent in SPE compared to MPE $(70.5 \%(43 / 61)$ versus $7.5 \%(3 / 40) ; \mathrm{p}<0.001)$, as were calcifications on the maternal surface of the placenta (Figure 4) which were more frequent in SPE compared to MPE (52.5\% (32/61) versus $17.5 \%(7 / 40) ; \mathrm{p}<0.001)$

Table 3. Distribution of the study population according to placenta weight.

\begin{tabular}{ccccc}
\hline & \multicolumn{4}{c}{ Pre-eclampsia } \\
\hline Variable & $\mathrm{N}=101$ & $\mathrm{n}=40$ & $\mathrm{n}=61$ & $\mathrm{p}$ \\
\hline Placenta weight $(\mathrm{g})$ & $483.02 \pm 123.48$ & $511.67 \pm 125.01$ & $454.37 \pm 121.96$ & $0.024^{*}$ \\
\hline $\mathrm{P}=$ p-value, ${ }^{*}=$ p-value $<0.05, \mathrm{~g}=$ grams. & & &
\end{tabular}

Table 4. Histological characteristics of the placentas of pre-eclamptic patients.

\begin{tabular}{|c|c|c|c|c|}
\hline Variables & $\begin{array}{c}\text { Total } \\
\mathrm{N}=101\end{array}$ & $\begin{array}{c}\text { MPE } \\
\mathrm{n}=40\end{array}$ & $\begin{array}{c}\text { SPE } \\
\mathrm{n}=61\end{array}$ & $\mathrm{p}$ \\
\hline Placenta weight (g) & $483.0 \pm 123.5$ & $511.7 \pm 125.0$ & $454.4 \pm 122$ & $0.024^{*}$ \\
\hline \multicolumn{5}{|l|}{ Villous maturity } \\
\hline Absent & $11(10.9)$ & $10(25.0)$ & $1(1.6)$ & \multirow[t]{4}{*}{$<0.001^{*}$} \\
\hline Weak & $34(33.7)$ & $17(42.5)$ & $17(27.9)$ & \\
\hline Moderate & $44(43.6)$ & $13(32.5)$ & $31(50.8)$ & \\
\hline Intense & $12(11.9)$ & $0(0.0)$ & $12(19.7)$ & \\
\hline \multicolumn{5}{|l|}{ Infarct } \\
\hline Yes & $15(14.9)$ & $2(5.0)$ & $13(21.3)$ & \multirow[t]{2}{*}{$0.024^{*}$} \\
\hline Not & $86(85.1)$ & $40(95.0)$ & $48(78.7)$ & \\
\hline \multicolumn{5}{|l|}{ Syncytial nodes } \\
\hline Yes & $46(45.5)$ & $3(7.5)$ & $43(70.5)$ & \multirow[t]{2}{*}{$<0.001^{*}$} \\
\hline Not & $55(54.5)$ & $37(92.5)$ & $18(29.5)$ & \\
\hline \multicolumn{5}{|l|}{ Calcifications } \\
\hline Yes & $39(38.6)$ & $7(17.5)$ & $32(52.5)$ & \multirow[t]{2}{*}{$<0.001^{*}$} \\
\hline Not & $62(61.4)$ & $33(82.5)$ & $29(47.5)$ & \\
\hline
\end{tabular}

$\mathrm{P}=\mathrm{p}$-value, ${ }^{*}=\mathrm{p}$-value $<0.05$. 


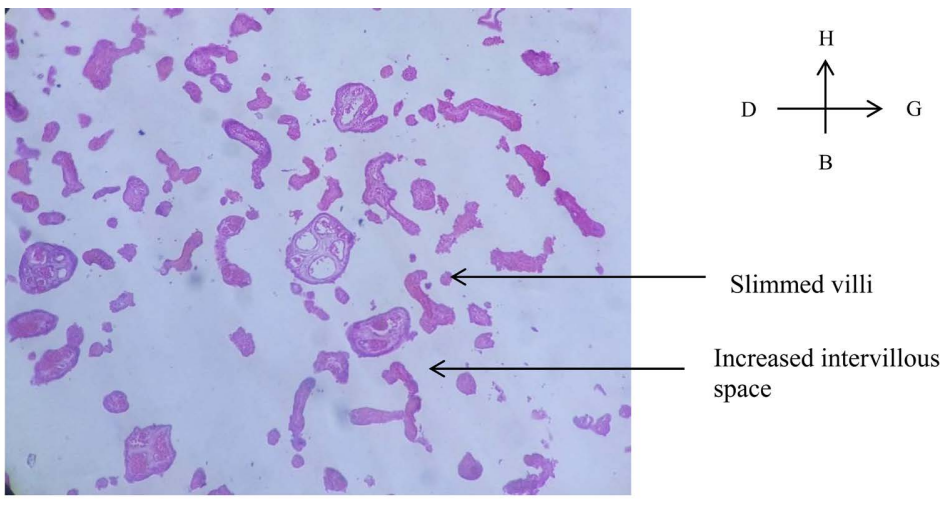

Figure 1. Microscopic image of a placental sample showing severe accelerated villous maturation.

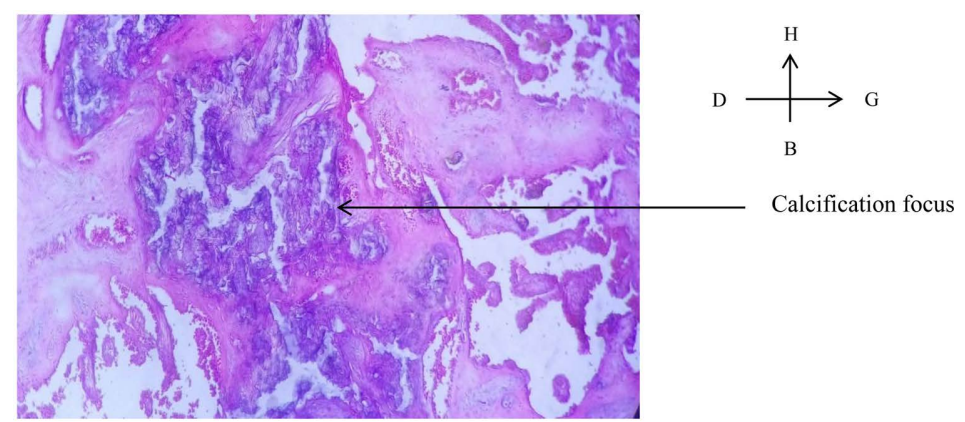

Figure 2. Microscopic image of a placental sample showing zones of calcification.

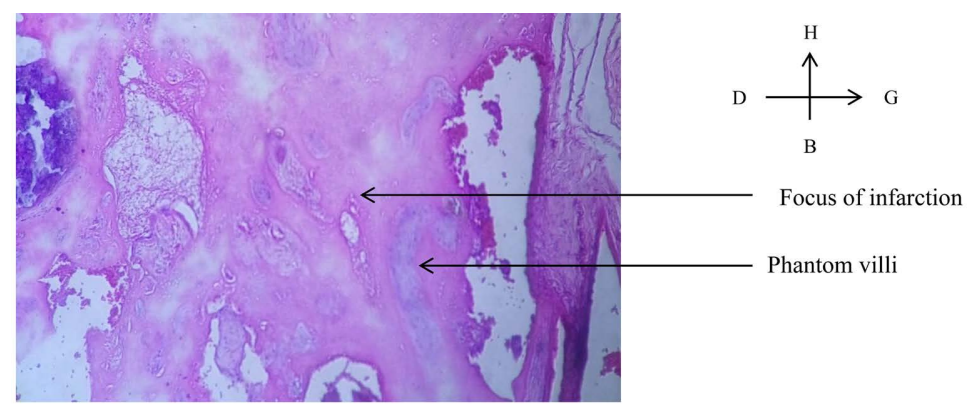

Figure 3. Microscopic image of a placental sample showing placental infarction.

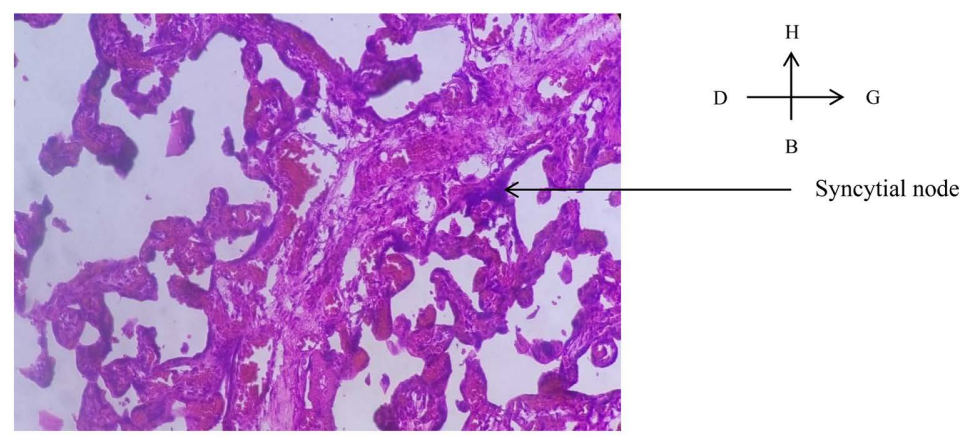

Figure 4. Microscopic image of a placental sample showing multiple syncytial nodes. 


\section{Discussion}

In our study, we investigated placental lesions in pre-eclamptic women and sought to determine whether these lesions correlated disease severity. The preeclamptic patients had a mean age in the environs of 30 (29.93 \pm 7.36 vs $28.28 \pm$ 7.18) and a low socioeconomic level, with no statistically significant difference between the two groups. Several authors in the literature have reported similar results [22] [23]. In their studies, Silva et al. and Lamminpää et al. reported that a low socioeconomic status increased the risk of developing PE by a factor of 5 (OR: 4.91; 95\% CI: 1.93, 12.52), while advanced maternal age (reproductive age) increased the risk of PE by a factor of 1.5 in a population of nearly 18000 women [24] [25]. This is thought to be due to decidualisation abnormalities linked to advancing maternal age, while the low socioeconomic status is associated with poor pregnancy follow-up, as well as other risk factors for PE [26] [27].

Most of the patients in our study had a parity of less than or equal to $1(\mathrm{n}=$ $0.55 ; 54.5 \%$ ) in line with the median parity of the study which is 1.00 (IQ: 1.00 3.00) with no significant difference between the two groups ( $p>0.05)$. This is consistent with the literature on pre-eclampsia which states that nulliparity and primiparity are established risk factors for pre-eclampsia. This is thought to be related to the lack of immune adaptation to pregnancy, the higher insulin resistance in primiparous women, as well as angiogenic and genetic factors [28].

Lack of pregnancy follow-up was the main factor significantly associated with severe pre-eclampsia in our study. Indeed, regular prenatal follow-up would prevent pregnant women from developing severe forms of pre-eclampsia through primary prevention (low dose aspirin, calcium) and early identification, management and monitoring of mild forms of PE [29] [30] [31] [32]

Patients with SPE had a significantly smaller mean placental weight than patients with MPE (454.37 \pm 121.96 vs $511.67 \pm 125.01 ; \mathrm{p}=0.024)$. Similar results were found by Rehman et al., Kishawa et al., and Dahlstrom et al., although the latter compared patients with PE to those without PE [33] [34]. In our study, the gestational ages at placental delivery were comparatively similar in both groups ( $36.46 \pm 3.68$ vs $37.55 \pm 3.08 ; \mathrm{p}=0.126)$, a finding which points to the effect PE severity on placental weight. Indeed, in pre-eclampsia, the failure of trophoblastic invasion and the resulting poor villous development are thought to be responsible for low placental weight.

The phenomena referred to above, result from the lack of molecular oxygen sensing, signalling, or the presence of extremely low oxygen levels in the intervillous spaces before the antioxidant responses become optimal. Thus, poor oxygen sensing would contribute to problems in the development of the fetoplacental vasculature and failure of maternal spiral artery invasion and remodelling. The change in oxygen content would be induced not only by the decrease in blood flow to the placenta, but also by the narrowing of the lumens of the spiral arteries, resulting in an increase in blood flow velocity (velocity flow). These alterations damage the fragile villi tree leading to excessive excretion of apone- 
crotic trophoblast fragments, inflammation, oxidative stress and ischaemia by hypoxia-reoxygenation phenomenon [35]

Placental lesions of pre-eclampsia (accelerated villous maturation, infarction, large syncytial nodes) were significantly present in patients with SPE compared to the MPE group ( $\mathrm{p}<0.001)$. In addition, confounding lesions such as calcifications were significantly higher in patients with SPE. Several authors have reported similar findings in the literature [36] [37] [38]. Weiner et al., found a greater number of placentas with a weight below the $10^{\text {th }}$ percentile and a mix of lesions due to defective maternal vascular perfusion (accelerated villous maturation, infarction, large syncytial nodes) in the SPE group compared with the MPE group ( $\mathrm{p}<0.001$ ). Furthermore, following multivariate analysis, these composite placental lesions were independently associated with SPE $(\mathrm{aOR}=1.75 ; 95 \% \mathrm{CI}$ 1.4 - 4.9; $\mathrm{p}<0.001)$.

Chronic malperfusion eventually leads to placental infarctions (Figure 3). These consist of collapsed maternal intervillous spaces and necrotic villi usually involving the maternal floor. These findings are not specific to PE and can occur with other conditions such as uterine anomalies, maternal cardiovascular disease and inherited or acquired maternal thrombophilias. Peripheral infarcts on the maternal face of the placenta are common at term and are usually not clinically significant if small. Perinatal morbidity is associated with infarcts representing more than $5 \%$ of the placental mass or having a diameter greater than $3 \mathrm{~cm}$. The infarcts are considered clinically severe (e.g., associated with foetal growth restriction or in utero foetal death) if $20 \%$ or more of the placenta is affected [11].

Specific histopathological findings that correlate poor maternal vascular perfusion include increased syncytial nodes $(>1$ in 3 - 5 terminal villi and/or $>10$ nuclei per node) (Figure 4), large syncytial nodes, villous agglutination (microinfarcts with villi collapsing on top of each other, especially in the centre of the parenchyma not involving the maternal surface), distal villous hypoplasia or accelerated villous maturation (reduced number of intermediate villi resulting in increased inter-villous space) (Figure 1), increased inter-villous fibrin (filling the lamina), and sclerotic narrowing of the arteries, arterioles, and intermediate trophoblast sheets along the basal plate [11]. However, the significance of these findings and their relationship to clinical disease is unclear.

Regarding calcifications (Figure 2), calcium deposits in the fibrin floor and septa are a normal finding associated with feeding and placental maturity at term and post-term. Villous calcification, however, is seen in villous necrosis with excessive peri-villous fibrin deposits, which may be associated with pathological conditions such as infarction, CMV infection, thrombosis and foetal death. When observed in preterm placentas, calcification of the floor and septa is attributed to senescence and therefore considered a feature of placental insufficiency [11].

Our study had some limitations. First the absence of sufficient funding prevented us from having a larger sample size necessary for more conclusive results. None the less, our findings were still valid. Also, other chronic placental condi- 
tions might have been linked to the placental lesions we described in our study.

\section{Conclusion}

PE remains a frequent pathology with dire consequences for the mother and the foetus in our context. Also, in line with our interests in identifying placental histopathological lesions, it appears that there are a set of composite lesions linked to underlying inadequate maternal vascular perfusion, especially in the severe form of the disease.

\section{Authors' Approval}

All authors agree to the submission of this article

\section{Authors' Contribution}

Essiben Felix and Ayissi Gregory designed the study and undertook data collection. Essiben Félix, Belinga Etienne and Foumane Pascal participated in the study design, performed data edits and statistical analyses, wrote the draft, and reviewed and finalized the manuscript. Ndolo Kondo Astrid, Ngo Dingom Madye and Ebong Cliford participated in statistical analyses, and edited and reviewed the final manuscript. Ojong Samuel Atomveng revised the document. All authors read and approved the final manuscript.

\section{Conflicts of Interest}

The authors declare no conflicts of interest regarding the publication of this paper.

\section{References}

[1] Anonymous (2020) Gestational Hypertension and Preeclampsia: ACOG Practice Bulletin, Number 222. Obstetrics \& Gynecology, 135, e237-e260. https://doi.org/10.1097/AOG.0000000000003891

[2] Noubiap, J.J., Bigna, J.J., Nyaga, U.F., Jingi, A.M., Kaze, A.D., Nansseu, J.R., et al. (2019) The Burden of Hypertensive Disorders of Pregnancy in Africa: A Systematic Review and Meta-Analysis. Journal of Clinical Hypertension, 21, 479-488. https://doi.org/10.1111/jch.13514

[3] Mboudou, E.T., Foumane, P., Priso, E.B., Dohbit, J., Minkande, J.Z., Nkengafac, W.M. and Doh, A.S. (2009) Hypertension au cours de la grossesse: Aspects cliniques et épidémiologiques a l'Hôpital Gynéco-Obstétrique et Pédiatrique de Yaounde, Cameroun. Clinics in Mother and Child Health, 6, 1087-1093. https://www.ajol.info/index.php/cmch/article/view/54323

[4] Abalos, E., Cuesta, C., Grosso, A.L., Chou, D. and Say, L. (2013) Global and Regional Estimates of Preeclampsia and Eclampsia: A Systematic Review. European Journal of Obstetrics and Gynecology and Reproductive Biology, 170, 1-7. https://doi.org/10.1016/j.ejogrb.2013.05.005

[5] Say, L., Chou, D., Gemmill, A., Tunçalp, Ö., Moller, A.B., Daniels, J., et al. (2014) Global Causes of Maternal Death: A WHO Systematic Analysis. Lancet Global Health, 2, E323-E333. https://doi.org/10.1016/S2214-109X(14)70227-X 
[6] Lain, K.Y. and Roberts, J.M. (2002) Contemporary Concepts of the Pathogenesis and Management of Preeclampsia. Journal of the American Medical Association, 287, 3183-3186. https://doi.org/10.1001/jama.287.24.3183

[7] Ditisheim, A., Sibai, B. and Tatevian, N. (2020) Placental Findings in Postpartum Preeclampsia: A Comparative Retrospective Study. American Journal of Perinatology, 37, 1217-1222. https://doi.org/10.1055/s-0039-1692716

[8] Meekins, J.W., Pijnenborg, R., Hanssens, M., McFadyen, I.R. and van Asshe, A. (1994) A Study of Placental Bed Spiral Arteries and Trophoblast Invasion in Normal and Severe Pre-Eclamptic Pregnancies. BJOG: An International Journal of $O b$ stetrics \& Gynaecology, 101, 669-674. https://doi.org/10.1111/j.1471-0528.1994.tb13182.x

[9] Makris, A., Thornton, C., Thompson, J., Thomson, S., Martin, R., Ogle, R., et al. (2007) Uteroplacental Ischemia Results in Proteinuric Hypertension and Elevated sFLT-1. Kidney International, 71, 977-984. https://doi.org/10.1038/sj.ki.5002175

[10] Maynard, S., Epstein, F.H. and Karumanchi, S.A. (2008) Preeclampsia and Angiogenic Imbalance. Annual Review of Medicine, 59, 61-78. https://doi.org/10.1146/annurev.med.59.110106.214058

[11] Roberts, D.J. (2022) The Placental Pathology Report. UpToDate. https://www.uptodate.com/contents/the-placental-pathology-report

[12] Ernst, L.M. (2018) Maternal Vascular Malperfusion of the Placental Bed. APMIS, 126, 551-560. https://doi.org/10.1111/apm.12833

[13] Tranquilli, A.L., Dekker, G., Magee, L., Roberts, J., Sibai, B.M., Steyn, W., et al. (2014) The Classification, Diagnosis and Management of the Hypertensive Disorders of Pregnancy: A Revised Statement from the ISSHP. Pregnancy Hypertension, 4, 97-104. https://doi.org/10.1016/j.preghy.2014.02.001

[14] Anonymous (2013) Hypertension in Pregnancy. Report of the American College of Obstetricians and Gynecologists' Task Force on Hypertension in Pregnancy. Obstetrics \& Gynecology, 122, 1122-1131.

[15] Ditisheim, A. and Sibai, B.M. (2017) Diagnosis and Management of HELLP Syndrome Complicated by Liver Hematoma. Clinical Obstetrics and Gynecology, 60, 190-197. https://doi.org/10.1097/GRF.0000000000000253

[16] Khong, T.Y., Pearce, J.M. and Robertson, W.B. (1987) Acute Atherosis in Preeclampsia: Maternal Determinants and Fetal Outcome in the Presence of the Lesion. American Journal of Obstetrics \& Gynecology, 157, 360-363. https://doi.org/10.1016/S0002-9378(87)80172-2

[17] Khong, T.Y., de Wolf, F., Robertson, W.B. and Brosens, I. (1986) Inadequate Maternal Vascular Response to Placentation in Pregnancies Complicated by Pre-Eclampsia and by Small-for-Gestational Age Infants. BJOG: An International Journal of Obstetrics \& Gynaecology, 93, 1049-1059. https://doi.org/10.1111/j.1471-0528.1986.tb07830.x

[18] Khong, T.Y. (1991) Acute Atherosis in Pregnancies Complicated by Hypertension, Small-for-Gestational-Age Infants, and Diabetes Mellitus. Archives of Pathology \& Laboratory Medicine, 115, 722-725.

[19] Pijnenborg, R., Anthony, J., Davey, D., Rees, A, Tiltman, A., Vercruysse, L., et al. (1991) Placental Bed Spiral Arteries in the Hypertensive Disorders of Pregnancy. BJOG: An International Journal of Obstetrics \& Gynaecology, 98, 648-655. https://doi.org/10.1111/j.1471-0528.1991.tb13450.x

[20] Davies, B.R. (1982) Decidual Vascular Lesions of Fibrinoid Necrosis/Atherosis. American Journal of Obstetrics \& Gynecology, 144, 118. 
https://doi.org/10.1016/0002-9378(82)90419-7

[21] Robertson, W.B., Brosens, I. and Dixon, G. (1976) Maternal Uterine Vascular Lesions in the Hypertensive Complications of Pregnancy. Perspectives in Nephrology and Hypertension, 5, 115-127.

[22] Gbadegesin, A., Soyemi, S., Agbara, J., Sobande, A. and Adebayo, S. (2019) Placental Malaria and Pre-Eclampsia from the Lagos State University Teaching Hospital, Ikeja, Lagos Nigeria. International Journal of Clinical Medicine, 10, 613-621. https://doi.org/10.4236/ijcm.2019.1011050

[23] Obiri, D., Erskine, I.J., Oduro, D., Kusi, K.A., Amponsah, J., Gyan, B.A., et al. (2020) Histopathological Lesions and Exposure to Plasmodium falciparum Infections in the Placenta Increases the Risk of Preeclampsia among Pregnant Women. Scientific Reports, 10, Article No. 8280. https://doi.org/10.1038/s41598-020-64736-4

[24] Lamminpää, R., Vehviläinen-Julkunen, K., Gissler, M. and Heinonen, S. (2012) Preeclampsia Complicated by Advanced Maternal Age: A Registry-Based Study on Primiparous Women in Finland 1997-2008. BMC Pregnancy and Childbirth, 12, Article No. 47. https://doi.org/10.1186/1471-2393-12-47

[25] Silva, L.M., Coolman, M., Steegers, E.A.P., Jaddoe, V.W.V., Moll, H.A., Hofman, A., et al. (2008) Low Socioeconomic Status Is a Risk Factor for Preeclampsia: The Generation R Study. Journal of Hypertension, 26, 1200-1208. https://doi.org/10.1097/HJH.0b013e3282fcc36e

[26] Lyall, F., Robson, S.C. and Bulmer, J.N. (2013) Spiral Artery Remodeling and Trophoblast Invasion in Preeclampsia and Fetal Growth Restriction Relationship to Clinical Outcome. Hypertension, 62, 1046-1054. https://doi.org/10.1161/HYPERTENSIONAHA.113.01892

[27] Ghi, T., Dall'Asta, A. and Valensise, H. (2018) Antenatal Care of Preeclampsia: From the Inverted Pyramid to the Arrow Model. Fetal Diagnosis and Therapy, 44, 81-84. https://doi.org/10.1159/000490047

[28] Luo, Z.C., An, N., Xu, H.R., Larante, A., Audibert, F. and Fraser, W.D. (2007) The Effects and Mechanisms of Primiparity on the Risk of Pre-Eclampsia: A Systematic Review. Paediatric and Perinatal Epidemiology, 21, 36-45. https://doi.org/10.1111/j.1365-3016.2007.00836.x

[29] Fadilah, D.R. and Devy, S.R. (2018) Antenatal Care Visits and Early Detection of Pre-Eclampsia among Pregnant Women. International Journal of Public Health Science (IJPHS), 7, 248-253. https://doi.org/10.11591/ijphs.v7i4.14769

[30] Sandström, A., Snowden, J.M., Bottai, M., Stephansson, O. and Wikström, A.K. (2021) Routinely Collected Antenatal Data for Longitudinal Prediction of Preeclampsia in Nulliparous Women: A Population-Based Study. Scientific Reports, 11, Article No. 17973. https://doi.org/10.1038/s41598-021-97465-3

[31] LeFevre, M.L. (2014) Low-Dose Aspirin Use for the Prevention of Morbidity and Mortality from Preeclampsia: U.S. Preventive Services Task Force Recommendation Statement. Annals of Internal Medicine, 161, 819-826. https://doi.org/10.7326/M14-1884

[32] World Health Organization (2013) Guideline: Calcium Supplementation in Pregnant Women. http://www.who.int/about/licensing/copyright form/en/index.html

[33] Rehmani, D., Jabeen, M., Jaffri, S.A. and Sultan, S. (2018) Frequency of Low Placental Weight in Preeclampsia. Journal of the Society of Obstetrics and Gynaecologists of Pakistan, 8, 223-226.

[34] Dahlstrøm, B., Romundstad, P., Øian, P., Vatten, L.J. and Eskild, A. (2008) Placenta Weight in Pre-Eclampsia. Acta Obstetricia et Gynecologica Scandinavica, 87, 608- 
611. https://doi.org/10.1080/00016340802056178

[35] Burton, G.J., Woods, A.W., Jauniaux, E. and Kingdom, J.C.P. (2009) Rheological and Physiological Consequences of Conversion of the Maternal Spiral Arteries for Uteroplacental Blood Flow during Human Pregnancy. Placenta, 30, 473-482. https://doi.org/10.1016/j.placenta.2009.02.009

[36] Paules, C., Youssef, L., Rovira, C., Crovetto, F., Nadal, A., Peguero, A., et al. (2019) Distinctive Patterns of Placental Lesions in Pre-Eclampsia vs Small-for-Gestational Age and Their Association with Fetoplacental Doppler. Ultrasound in Obstetrics \& Gynecology, 54, 609-616. https://doi.org/10.1002/uog.20350

[37] Weiner, E., Feldstein, O., Tamayev, L., Grinstein, E., Barber, E., Bar, J., et al. (2018) Placental Histopathological Lesions in Correlation with Neonatal Outcome in Preeclampsia with and without Severe Features. Pregnancy Hypertension, 12, 6-10. https://doi.org/10.1016/j.preghy.2018.02.001

[38] Pietro, L., Paulo De Siqueira Guida, J., De Moraes Nobrega, G., Antolini-Tavares, A. and Laura Costa, M. (2021) Achados placentários na pré-eclâmpsia pré-termo e a termo: Uma revisão integrativa da literatura [Placental Findings in Preterm and Term Preeclampsia: An Integrative Review of the Literature]. Revista Brasileira de Ginecologia e Obstetrícia, 43, 560-569. https://doi.org/10.1055/s-0041-1730292 